\title{
The Interrelation between the Professional Judgment of the Accountant and the Quality of Financial Reporting
}

\author{
Kulikova L.I. \\ Kazan Federal University, Institute of Management, Economics and Finance, 420008, Kazan, Russia
}

Grigoryeva L.L.

Kazan Federal University, Institute of Language, 420008, Kazan, Russia

Gubaidullina A.R.

Kazan Federal University, Institute of Management, Economics and Finance, 420008, Kazan, Russia

Doi:10.5901/mjss.2014.v5n24p61

\begin{abstract}
The urgency of the given research is defined by the fact that the improvement of financial reporting quality which is the basic source for the conduction of enterprise's financial state and results of activity analysis is continuously connected to the efficiency of assets and liabilities, their quantification and classification. The purpose of the research is to consider the basic approaches to the definition of financial reporting quality, to reveal interrelation between professional accounting judgment regarding accounting objects and forecast value of information introduced to users.
\end{abstract}

Keywords: quality, limits the quality of financial reporting prognostic value of information, the discounted cost, qualitative characteristics of information for professional accounting judgment international standards

\section{Introduction}

Under conditions of enhancing of interest in information introduced to accounting financial reporting, the problem of its refinement arises. It is important to note that the notion «quality» is rather versatile. Thus, in philosophical understanding it is the totality of essential attributes, peculiarities and characteristics which distinguish one object or phenomenon from another and make them certain. Series of international standards describing requirements to the management system of organizations and enterprises quality - ISO 9000 defines quality as the totality of the object's characteristic features showing relation to its capability to satisfy the established and expected consumer's requirements [1]. From the technical and economic points of view, quality cannot be statical in the process of production, science, and technics development; from the juridical point of view, the notion being analyzed is statical and signifies correspondence to the definite, affirmed beforehand and co-ordinated criteria. In other words, legal appraisal of the production quality signifies the level of correspondence of production features compared to the complex and level of requirements established and fixed in the corresponding properly executed document.

Analysis of the notions of class quality allows to form its definition in regard to financial reporting. Thus, quality of financial reporting is the totality of accounting reporting characteristics regarding their capability to satisfy the established and expected needs of potential professional users of accounting reporting under conditions of its actual use in taking economic decisions [3].

The quality of accounting information is defined by how much information needs of the interested users can be satisfied from the possibility to make substantiated economic decisions point of view. It is proved by the fact that in accordance with Conception of accounting in Russian market economy, the basic criterion of accounting information quality being its usefulness in terms of the position of managing decisions taking by the interested users.

\section{Materials and Methods}

Theoretical foundation of the research is based on fundamental accounting conceptions, hypotheses and approaches 
presented in classical and modern academic economic literature. Methodological foundation of this work is the systematic approach to the processes and phenomena being investigated, methods of dialectical and formal logics. A wide range of methods were used: comparative analysis, synthesis, systematization and generalization of theoretical materials, summary and grouping, analytical procedures and other methods.

\section{Results and Discussion}

Conceptual bases of preparation and presentation of financial report turn out to be ideal vision of financial reporting which in practice cannot be achieved [14]. This is proved by the fact that financial reporting is largely based on assessments, judgments, since significant role in the formaton of accounting financial reporting belongs to professional judgment of an accountant. Conceptual bases give general definition of qualitative characteristics of useful financial information, define basic (fundamental) characteristics which make information useful and improving qualitative characteristics which enhance the usefulness of information and define the sole limitation to useful financial accounting - expenditures [5].

Frequently the choice of the ways of accounting may be connected to the necessity to make choice between this or that requirement. For example, methods providing plenitude of economic life facts accounting may not completely meet such a requirement as rationality and vice versa. To provide timeliness of information, occasionally it is necessary to sacrifice the plenitude and reliability of data; at the same time the expectation of moment when all details of economic operations become precisely known allows to reach reliability of information but makes it useless for timely decision taking by the users [8].

In such situations the company's management and specialists should evaluate the level of influence of the method chosen upon financial information usefulness and decide which requirement to choose. Relative importance of separate requirements in different economic conditions is determined by professional judgment [6].

From our point of view, professional judgment could be characterized as a proved opinion of a professional accountant given under conditions of uncertainty during qualification, cost measurement, classification and evaluation of economic facts significance for purpose of accounting reporting based on the available at the this point entire, true and objective information and peculiarities of managing subject's functioning [3].

Professional judgment within concrete decision should possess two features:

- decrease entropy in the accounting system (exclude variativeness in parameters of accounting politics in regard to homogeneous group of economic life factors);

- $\quad$ introduce value for the accounting system being modelled during the presentation of finacial reporting [11].

Threfore, it is possible to conclude that since the accountant's professional judgment means conscious influence upon the shape and content of accounting balance within working principles and standards aimed at the formation the of indices corresponding strategic goals of the enterprise's development set beforehand, it turns out to be one of the basic means of quality management. This occurs by the following directions: variation of indices of accounting balancing with the help of its items' assessment and change of the assets and liabilities structures. This fact can influence prognostic value of information and thereby influence its quality [9].

Nevertheless, the enhancement of financial reporting quality becomes complicated because of its economic nature, since it is restricted by a number of aspects: accounting reporting cannot deliver all information which is required by the users (it is necessary to include information about economic, political, branch events from other sources); accounting is not intended to reflect the company's cost, it must provide information which helps the users to estimate such cost: each group of the main users may have their own information needs, and these needs of individual groups of users may conflict with each other.

Apart from the above said, financial reporting traditionally contained information about previous events, and recently increase of need in forecasting information is observed [10]. At the same time, data for the accounting date or period could be used to forecast future [13]. The degree of these results correspodence made during such an investigation is determined by the quality of information provision.

In connection with this fact large practical importance belongs to the methods of perspective analysis which allow to take managing decisions evaluating possible situations and making choice between several alternative variants. The key moment during preparation of financial reporting is determination of initial and further evaluation of assets and company's liabilities since reliability and reality of the given information depend on it and therefore validity of the economic decisions accepted on its basis [12]. Under such conditions particular urgency is given to validity of the way of assessment which concerns the jurisdiction of the accountant's professional judgment.

Reflection of assets and liabilities in accounting (financial) reporting according to the initial cost does not always allow to take into account influence of such macroeconomic factors as depreciation of national currency, inflation 
background that can lead to significant misrepresentation of information accounting value. In connection to this it is necessary to seek other approaches to consider influence of macroeconomic factors on the assessment of assets and liabilities in accordance with forecast of funds movement and individual entrepreneurers' preferences, i.e. the use of the discounted cost.

The discounted cost as a type of assessment allows to determine the cost of assets and liabilities from the postion of temporal cost of money concept. The use of the discounted cost during the assessment of assets and liabilities is proposed by a wide range of international standards. In particular, to them belong IFRS 2 «Reserves», IFRS 16 «Main means», IFRS 38 «Nonmaterial assets» - concerning assessment of assets purchased with deferment of payment, ISFR 39 «Financial instruments : recognition and payment», IFRS 40 «Investment real estate», IFRS 41 «Agriculture», IFRS 3 «Unification of business», IFRS 5 «Long-term assets intended for sale and discontinued activity» with determination of fare cost of financial assets, IFRS 18 « Profit» with provision of counterpart with delay in payment determined by discounting of future entries sum; IFRS 36 «Depreciation of assets» with determination of value from the assets use figured out by discounting of future cash flows the receipt of which is anticipated from the assets, IFRS18 «Profit» with recognition of profit in size of the discounted sum of future entries in the event of the provision of counterpart with delay in payment for a long time, IFRS 17 «Rent» with evaluation of the discounted cost of minimal rent payments and evaluation of gross investments in rent. Despite the discounting technique unified for all cases of its application, calculation of the discounting rate being used and determination of discounting period differ in each separate case and concern jurisdiction of the accountant's professional judgment [2].

At the same time it is important to note that increase in forecast value of information is possible to reach by decrease in part of partial assessments in choice of the object's accounting, its assessment and further reflection in accounting [7]. Nevertheless, as it was mentioned above, according to Russian and international law qualification and quantification of objects concern jurisdiction of the accountant's professional judgment. Within the formation of accounting politics, the choice of accounting type is granted capable of influencing in a large degree indices of the company's financial state, this can significantly influence the quality of accounting.

In connection to this fact, important role is given to the comparison of information - qualitative characteristics which give the users opportunity to identify and understand similarities and differences between the parts of financial reporting [7]. Since the users' decisions involve choice between the alternatives, information about reporting company is more useful if it is compared to analogous information about other companies and analogous information about the given company for another period or date.

Control carries out an important function in the system of the reporting users' provision with the quality information and assists in the enhancement of information reliability, correspondence of indices of accounting reporting with the established requirements. Hold of control over accounting reporting quality is directed to the protection of public interests and provision of truthfulness of official accounting reporting, i.e. refers to financial regulating and is of public and law nature.

Scholar A.F. Sokolovsky points out on the existence of two main ways to verify quality : preoperating and consumer (operating). The first variant when the quality is determined before consumption is inaccurate: it does not show how in the end quality satisfies the users' needs. Only consumption can reveal quality more precisely. From this concept's application to the control of financial reporting quality, audit of financial reporting turns out to be preoperating which verifies validity of the accountant's professional judgment to evaluation of economic life facts and their representation in reporting [9]. The problem of consumer control is that each user because of their subjective opinion can differently estimate the quality of the given accounting information. This fact determines the subject's further actions: to accept the received information as quality or deny it because of the lack of evidence. Thus, because of the existence of different understanding of information quality by different users it is necessary to define general criteria for quality.

Subjective criteria of evaluation of accounting information quality are determined by the users from their information needs and ideas on the level of their satisfaction point of view. And each user ranks the given in the accounting (financial) reporting information about the quality marking out (by level of significance) the first rank and the second rank qualities in the hierarchy of properties of the information presented.

Objective criteria of the quality of the accounting information are determined by calculating on the basis of the study of objective data (accounting and analytical indices) reflecting the results of the events allowing to assess the accounting reporting quality. And to obtain the objective criteria of assessment, it is necessary to apply calculating methods to the whole totality of accounting information namely to evaluate its importance for all groups of users.

According to I.A. Slobodnyak, the formation of professional judgment has:

- objective side when the object's essence itself is studied and becomes a subject of professional judgment:

- subjective side which is the study of different specialists' points of view on the basis of which personal 
subjective opinion of each specialist is formed [12].

\section{Conclusion}

Thus, namely the users' information needs determine the set of the basic criteria for the quality of accounting information. Conceptual bases of financial reporting presentation determine the concepts which underlie the accountant's professional judgment and these concepts are the aim which is necessary to seek. This definition of aim is ideal and required for further development of financial reporting and enhancement of its quality.

\section{References}

GOST R ISO 9001-2009. Quality management system. Requirements. Moscow: Federal State Unitary Enterprise "Standartinform," 2009. $31 \mathrm{sec}$

Billio M., Getmansky M., Lo A., and Pelizzon L. Econometric Measures of Connectedness and Systemic Risk in the Finance and Insurance Sectors// Journal of Financial Economics 3, 2012, vol. 104, pp. 535-559

Gubaidullina A.R. Accounting principles determining the use of professional accounting judgement in the conditions of transition to international financial reporting standarts // International accounting. No. 28, 2012

Jeffrey T. Doyle, Matthew J. Magilke. Decision Usefulness and Accelerated Filing Deadlines // Journal of Accounting Research. Vol. 51, No. 3 (june 2013), pp. 549-581(DOI: 10.2307/23473300)

Kulikova L.I., Goshunova A.V. Measuring efficiency of professional football club in contemporary researches. World Applied Sciences Journal, 2013; 25(2): 247-257.

Kulikova L.I., Semenichina N.B. Preparation of the actuarial balance sheet based on the present value of assets and liabilities of the going concern. Life Science Journal. 2014;11(11s):603-607.

Lang M, Lins K. V. and Maffet M. Transparency, Liquidity, and Valuation: International Evidence on When Transparency Matters Most /I Journal of Accounting Research. Vol. 50, No. 3 (JUNE 2012), pp. $729-774$ (DOI: 10.2307/41477990)

Merton R. C., Billio M., Getmansky M., Gray D., Andrew W. Lo, Pelizzon L. On a New Approach for Analyzing and Managing Macrofinancial Risks (corrected) // Financial Analysts Journal. Vol. 69, No. 2, 2013

Polisyuk G.B., Sukhacheva G.I. The content of the category of "quality of financial statements"/ Polisyuk GB, Sukhacheva GI // International accounting, No. 47, 2011

Rennekamp K. Processing Fluency and Investors' Reactions to Disclosure Readability // Journal of Accounting Research. Vol. 50, No. 5 (DECEMBER 2012), pp.1319-1354 (DOI: 10.2307/41680547)

Shahid Ebrahim M., Sourafel Girma, Eskandar Shah M., Jonathan Williams. Dynamic capital structure and political patronage: The case of MalaysiaOriginal Research Article// International Review of Financial Analysis. Volume 31, pp. 117-128.

Slobodnyak I.A. The use of professional judgment in the formation of accounting and analytical information on the income of the accounting organization for management reporting Slobodnyak IA / International accounting. Vol.27, 2011

Stephen C. Sexauer and Laurence B. Siegel. A Pension Promise to Oneself // Financial Analysts Journal 6, 2013, Volume 69, pp. 13-32

Sungjun C. New return anomalies and new-Keynesian ICAPM. International Review of Financial Analysis, Volume 29, September 2013, pp. 87-106 (DOI: 10.1016/j.irfa.2013.04.003)

Thomas J. Sargent. Rational Expectations and Ambiguity (corrected) // Financial Analysts Journal. Vol. 70,2014, No. 2, pp. 14-19. 